\title{
Taste dysfunction in multiple sclerosis
}

\author{
Richard L. Doty ${ }^{1,2}$ (D) Isabelle A. Tourbier ${ }^{1,2} \cdot$ Dzung L. Pham $^{3} \cdot$ Jennifer L. Cuzzocreo $^{4}$ • \\ Jayaram K. Udupa ${ }^{5}$ - Bilge Karacali ${ }^{6}$ Evan Beals ${ }^{1,7}$ - Laura Fabius ${ }^{1,2}$. \\ Fidias E. Leon-Sarmiento $^{1,2}$ - Gul Moonis ${ }^{8}$ - Taehoon Kim ${ }^{1,2}$ - Toru Mihama ${ }^{1,2}$. \\ Rena J. Geckle ${ }^{9}$ David M. Yousem ${ }^{9}$
}

Received: 28 October 2015/Revised: 9 January 2016/ Accepted: 11 January 2016/Published online: 25 January 2016 (c) Springer-Verlag Berlin Heidelberg 2016

\begin{abstract}
Empirical studies of taste function in multiple sclerosis (MS) are rare. Moreover, a detailed assessment of whether quantitative measures of taste function correlate with the punctate and patchy myelin-related lesions found throughout the CNS of MS patients has not been made. We administered a 96-trial test of sweet (sucrose), sour (citric acid), bitter (caffeine) and salty $(\mathrm{NaCl})$ taste perception to the left and right anterior (CN VII) and posterior (CN IX) tongue regions of 73 MS patients and 73 matched controls. The number and volume of lesions were assessed using quantitative MRI in 52 brain regions of 63 of the MS
\end{abstract}

Richard L. Doty

richard.doty@uphs.upenn.edu

1 Smell and Taste Center, Perelman School of Medicine, University of Pennsylvania, 5 Ravdin Building, 3400 Spruce Street, Philadelphia, PA 19104-4823, USA

2 Department of Otorhinolarynology: Head and Neck Surgery, Perelman School of Medicine, University of Pennsylvania, Philadelphia, PA 19104, USA

3 Center for Neuroscience and Regenerative Medicine, Henry Jackson Foundation, Bethesda, MD, USA

4 Department of Neurology, Johns Hopkins School of Medicine, Baltimore 21287, MD, USA

5 Medical Imaging Section, Department of Radiology, Perelman School of Medicine, University of Pennsylvlania, Philadelphia 19104, PA, USA

6 Electrical and Electronics Engineering Department, İzmir Institute of Technology, Urla, Izmir 35430, Turkey

7 Department of Psychology, Michigan State University, 48824 East Lansing, MI, USA

8 Department of Radiology, Columbia University Medical Center, New York, NY 10032, USA

9 Department of Radiology, The Johns Hopkins Hospital, Baltimore, MD 21287, USA patients. Taste identification scores were significantly lower in the MS patients for sucrose $(p=0.0002)$, citric acid $(p=0.0001)$, caffeine $(p=0.0372)$ and $\mathrm{NaCl}$ $(p=0.0004)$ and were present in both anterior and posterior tongue regions. The percent of MS patients with identification scores falling below the 5th percentile of controls was $15.07 \%$ for caffeine, $21.9 \%$ for citric acid, $24.66 \%$ for sucrose, and $31.50 \%$ for $\mathrm{NaCl}$. Such scores were inversely correlated with lesion volumes in the temporal, medial frontal, and superior frontal lobes, and with the number of lesions in the left and right superior frontal lobes, right anterior cingulate gyrus, and left parietal operculum. Regardless of the subject group, women outperformed men on the taste measures. These findings indicate that a sizable number of MS patients exhibit taste deficits that are associated with MS-related lesions throughout the brain.

Keywords Multiple sclerosis - Magnetic resonance imaging $\cdot$ Taste $\cdot$ Chemosensory transduction $\cdot$ Taste disorders $\cdot$ Sex differences

\section{Introduction}

The influence of multiple sclerosis (MS), the most common neurologic disease of young adulthood, on taste perception has received scant attention, despite the fact that 10-15\% of community dwelling patients with MS suffer from malnutrition [1]. Based on self-report or cursory sensory testing, MS-related taste disorders have been assumed to be rare, often being $<5 \%$ [2-7]. However, people reporting taste deficits typically have olfactory, not taste, dysfunction [7], and are generally inaccurate in recognizing true taste dysfunction when present [8]. Studies employing 
electrogustometry and other quantitative taste tests typically observe somewhat higher prevalence rates. For example, Rollin [9] reported that 9 of 75 MS patients exhibited elevated electrogustometric thresholds (12\%), although specific details of the testing were lacking. Three relatively recent whole-mouth taste studies have reported levels of disturbance in approximately $20 \%$ of MS patients, although distinctions among taste qualities and tongue regions were not made [10-12]. In the sole study to examine possible associations between taste test scores and MS-related lesions, the identification scores of 25 subjects, combined across taste qualities, were inversely correlated with lesion numbers $(r=-0.49)$ and lesion volumes $(r=-0.52)$ within the "olfactory brain", i.e., the piriform and entorhinal cortices, frontal agranular regions of the insular lobe up to the anterior commissure, and the orbitofrontal cortex [12].

In this study, we administered a sensitive and wellvalidated 96-trial taste test to a relatively large number of MS patients and matched controls to more definitively assess the influences of MS on taste function. The study had four main objectives: first, to establish the frequency and magnitude of taste deficits in the MS patients; second, to determine whether such dysfunction, when present, is uniform across disparate tongue regions; third, to determine whether the MS-related taste deficits differ among sweet, sour, bitter and salty tasting stimuli; and fourth, to evaluate whether taste test scores are associated with the number and volume of MS-related lesions in 26 brain regions within each side of the brain (i.e., 52 total brain structures).

\section{Materials and methods}

\section{Subjects}

The subjects were 73 patients with well-documented MS and 73 healthy controls matched to the patients on the basis of age, sex, ethnicity, and education (Table 1). Approximately half came from within the University of Pennsylvania Health System, whereas the remainder came from outside this system. Most were recruited through their physician, MS support group, or a local MS newsletter. Controls were obtained through advertisements placed in newspapers or fliers posted in the Hospital of the University of Pennsylvania or around the University's campus. Individuals were excluded from consideration if they had a positive medical history for non-MS disorders that could confound not only the gustatory, but also the other sensory tests performed in the program. These included Bell's palsy, chronic rhinosinusitis, chronic lung infection, epilepsy, emphysema, liver disease, stroke, seizure disorder, neurodegenerative disease other than MS, schizophrenia, psychosis, bipolar disorder, dementia, amnesia, depression requiring medication or hospitalization, chronic alcoholism or drug abuse, brain surgery, or facial injuries or head trauma leading to loss of consciousness, among others.

This research was a component of a comprehensive program that evaluated auditory, olfactory, gustatory, vestibular, and neuropsychological function of the same set of MS patients. Findings from the other elements of the program have been published [13] or are in preparation for publication. The study was approved by the University's Office of Regulatory Affairs and all subjects provided informed written consent. The research was performed in accordance with the ethical principles of the Declaration of Helsinki (1964) and its later amendments. Each subject was paid $\$ 20$ per hour for participation and was reimbursed for travel and food expenses.

\section{Taste test protocol}

The standardized taste test that was employed is described elsewhere $[14,15]$. Briefly, $15 \mu \mathrm{L}$ of single concentrations of sucrose $(0.49 \mathrm{M})$, sodium chloride $(0.31 \mathrm{M})$, citric acid $(0.015 \mathrm{M})$, and caffeine $(0.04 \mathrm{M})$, equated for viscosity by the addition of cellulose to minimize stimulus migration, were presented via an Eppendorf pipette to the left and right sides of the tongue tip and on or near the left and right lateral circumvallate papillae. Each subject indicated whether a given stimulus tasted sweet, sour, bitter or salty by pointing to names on a chart before retracting the tongue and orally rinsing with purified water. A total of 96 stimulus trials and accompanying rinses was employed ( 4 tastants $\times 6$ trials $\times 4$ tongue regions). Additionally, perceived intensity was rated on a visually graded category scale with anchors of "very weak" and "very strong" and a logarithmic visual density background denoting non-linear increasing sensation magnitudes [16].

\section{Imaging protocol}

All MS patients underwent, usually on the same day as the sensory testing, thin section magnetic resonance imaging (MRI) of the brain with gadolinium enhancement using a General Electric (Milwaukee, WI) 1.5-T Signa scanner employing a standard head coil. Usable images were available for 63 of the patients and were employed to quantify the number of lesions and volumes in multiple brain regions. The MRI evaluations included fluid-attenuated inversion recovery (FLAIR) and double-echo long-TR axial scans with 3-mm thick slices through the entire brain. The matrix was $256 \times 192$ pixels and the field of view was 
$240 \mathrm{~mm}^{2}$, allowing for detailed assessment of MS-related lesion intensity within selected brain regions. Brain volumes were extracted semi-automatically using a combination of thresholding, morphological operators, and region growing, followed by manual refinement [17, 18]. Lesions were then defined semi-automatically by first using a fuzzy segmentation algorithm applied to the multichannel brain extracted images $[19,20]$. This algorithm was modified to model lesion intensities as outliers, similar to the approach described by Van Leemput et al. [21]. The resulting segmentation was inclusive of all lesions but included falsepositives that were manually removed by a trained operator. If a lesion fell into two regions, it was counted as a lesion in both of the regions. However, its volume was parceled between the two regions into which it fell. The intra-rater reliability intraclass correlation coefficient for our approach based upon 10 cases repeated twice by the same operator was above 0.99. Regions of interest were defined automatically by applying a high-dimensional, non-linear registration of a manually parcellated atlas image to each subject (Figs. 1, 2) [22, 23]. The atlas was based on a T1-weighted MRI from a healthy subject. Thus, the regions of interest were defined by manually labeling a template MRI brain and deforming this image into each subject's brain image using the HAMMER algorithm. The labels were transferred with this deformation. A total of 26 brain regions were defined for each side of the brain (i.e., 52 total brain structures; Table 2). These regions were chosen to incorporate well-established brain structures applicable to a range of sensory studies that are being performed on the data set.

\section{Statistical analyses}

All statistical analyses were made using modules from SYSTAT [24]. Initially we determined the number of MS

Table 1 Basic demographics of the MS and matched control subjects

\begin{tabular}{|c|c|c|c|c|c|c|c|c|}
\hline $\begin{array}{l}\text { Subject } \\
\text { group }\end{array}$ & $\begin{array}{l}\text { Sample } \\
\text { size }\end{array}$ & $\begin{array}{l}\text { Mean } \\
\text { age (SD) }\end{array}$ & $\begin{array}{l}\text { Ethnicity } \\
\text { W/B (\% W) }\end{array}$ & $\begin{array}{l}\text { Mean years } \\
\text { education (SD) }\end{array}$ & $\begin{array}{l}\text { Number of smokers/ } \\
\text { non-smokers } \\
\text { (\% smokers) }\end{array}$ & $\begin{array}{l}\text { Mean (SD) } \\
\text { disease } \\
\text { duration }\end{array}$ & $\begin{array}{l}\text { Mean EDSS } \\
\text { score (SD) }\end{array}$ & $\begin{array}{l}\text { Disease } \\
\text { classification }\end{array}$ \\
\hline MS_Males & 21 & $\begin{array}{l}45.24 \\
(11.42)\end{array}$ & $\begin{array}{l}17 / 4 \\
(81.0)\end{array}$ & $\begin{array}{l}15.10 \\
(2.74)\end{array}$ & $\begin{array}{l}5 / 16 \\
(23.8 \%)\end{array}$ & $\begin{array}{l}7.36 \\
(3.96)\end{array}$ & $\begin{array}{l}4.54 \\
(1.80)\end{array}$ & $\begin{array}{l}\text { RR: } 15 \text {; PP: } 2 \text {; } \\
\text { SP: } 2 \text {; U: } 2\end{array}$ \\
\hline MS_Females & 52 & $\begin{array}{l}45.60 \\
(8.61)\end{array}$ & $\begin{array}{l}38 / 14 \\
(73 \%)\end{array}$ & $\begin{array}{l}14.52 \\
(2.20)\end{array}$ & $\begin{array}{l}12 / 40 \\
(23.1 \%)\end{array}$ & $\begin{array}{l}7.84 \\
(6.61)\end{array}$ & $\begin{array}{l}3.36 \\
(1.60)\end{array}$ & $\begin{array}{l}\text { RR: 42; PP: } 1 \text {; } \\
\text { SP: 4; U: } 5\end{array}$ \\
\hline C-Males & 21 & $\begin{array}{l}45.43 \\
(10.78)\end{array}$ & $\begin{array}{l}17 / 4 \\
(81.0)\end{array}$ & $\begin{array}{l}15.10 \\
(3.23)\end{array}$ & $\begin{array}{l}4 / 17 \\
(19.0 \%)\end{array}$ & - & - & - \\
\hline $\mathrm{C}$-Females & 52 & $\begin{array}{l}46.60 \\
(9.35)\end{array}$ & $\begin{array}{l}38 / 14 \\
(73.1 \%)\end{array}$ & $\begin{array}{l}15.51 \\
(2.36)\end{array}$ & $\begin{array}{l}5 / 47 \\
(9.6 \%)\end{array}$ & - & - & - \\
\hline
\end{tabular}

$W / B$ white/black, $M S$ multiple sclerosis, $C$ control, $R R$ relapsing remitting, $P P$ primary progressive, $S P$ secondary progressive, $U$ unknown. EDSS Expanded Disability Status Score based on 29 patients

No significant differences are present between any of the means or frequencies across the MS and control groups or between the males and females
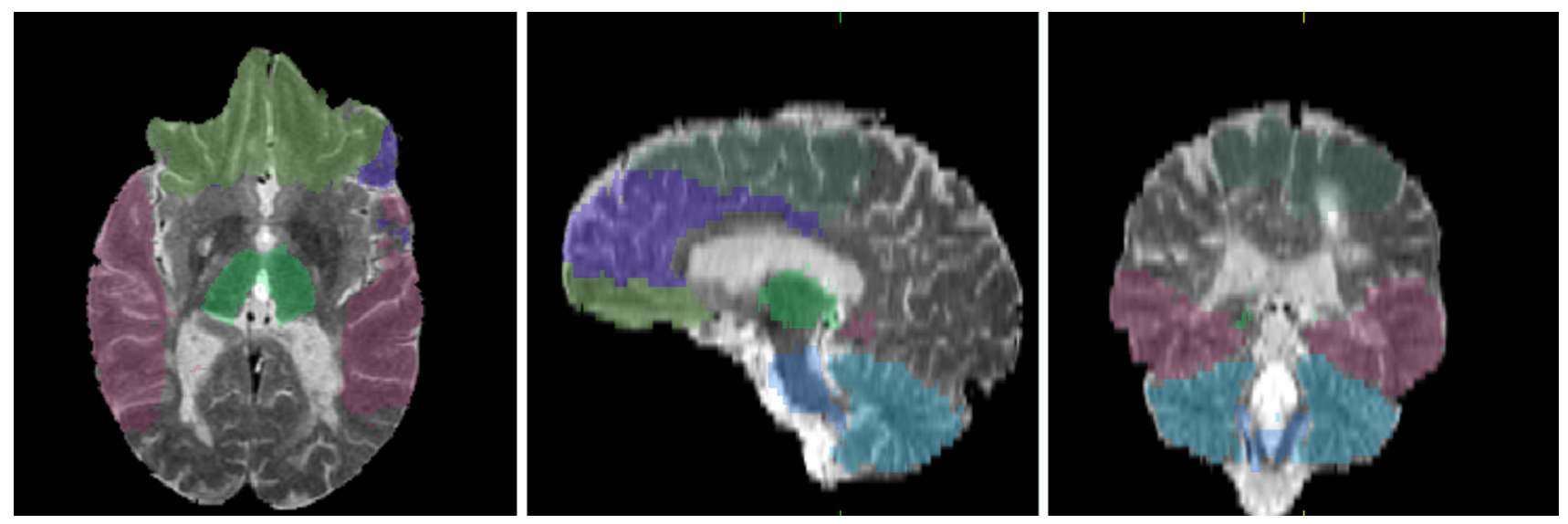

Fig. 1 Triplanar view of registration-based parcellation of the brain into superior, medial, and inferior frontal lobes, temporal lobes, cerebellum, thalamus, and brainstem. Other labels denoted in the text are not shown because several regions overlap. See text for details 

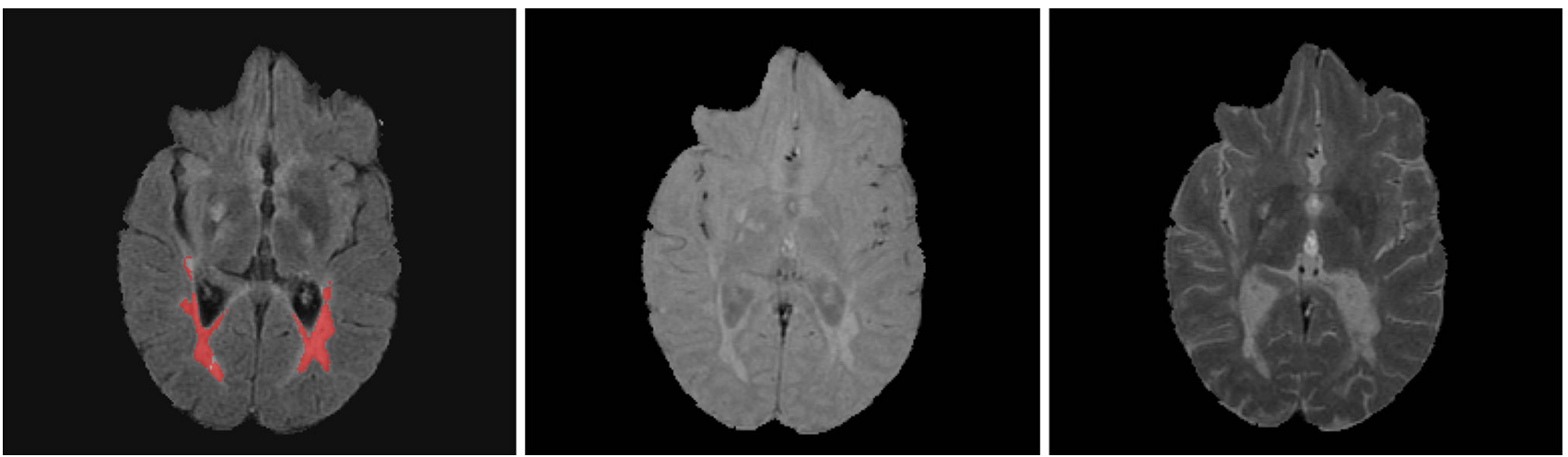

Fig. 2 Left axial slice of the FLAIR image with semi-automatic lesion segmentation highlighted in red. Middle proton density weighted image. Right T2-weighted image. See text for details

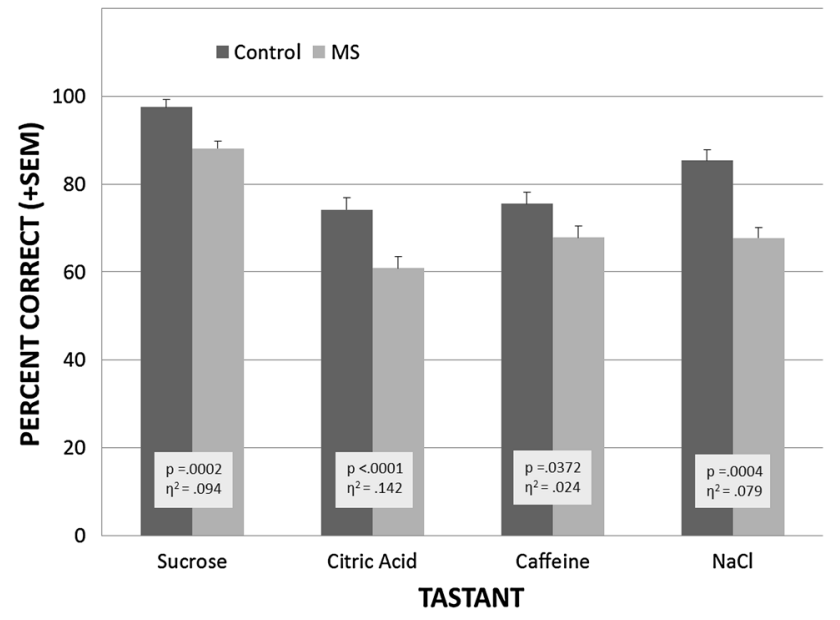

Fig. 3 Mean $( \pm$ SEM) percent correct taste identifications for sweet (sucrose), sour (citric acid), bitter (caffeine) and salty (sodium chloride) tasting stimuli for the 146 subjects of the study (73 multiple sclerosis patients and 73 matched controls). The dependent measure reflects the percent of correct responses from a total of 24 trials for each stimulus (6 trials $\times 4$ tongue regions). Copyright (C) 2015 Richard L Doty. See text for details

subjects who performed more poorly than the control subjects, as determined by taste identification test scores falling below the 5th percentile of those of the controls. Preliminary analyses were performed on each test measure and taste stimulus to explore the influences of key variables on the dependent measures. Smoking behavior, disease duration, and handedness did not meaningfully contribute to any of the analyses and were dropped from subsequent models. Since tongue side was not significant, the data from the two sides of the tongue were combined for subsequent analyses, resulting in anterior (CN VII) and posterior (CN IX) measures. The final model, performed on the data for each tastant separately, was an analysis of covariance (ANCOVA) with the between group factors of patient group (MS, control) and sex (M,F), and the within group factor of tongue region (anterior, posterior). Age served as a covariate. To simplify the presentation of results, $F$ values and degrees of freedom are not reported in the text; $\eta^{2}$ values, which reflect effect sizes, are reported only when significant $p$ values are present.

Because the lesion frequency distributions were strongly skewed to the right, non-parametric Spearman correlations were computed to determine whether meaningful associations were present among the taste measures and the two lesion measures (lesion number, volume) within the target brain regions. $p$ values were unadjusted for multiple comparisons to avoid type II errors and associated problems [25, 26]; however, the number of computations was limited to subgroups with lesion activity. In these analyses, the lesion data from the left and right sides of the brain were retained as separate entities in light of possible lateralized associations with lesions in some brain regions [27, 28].

\section{Results}

\section{Taste quality identification}

The percent of MS patients whose overall taste identification test scores fell below the 5th percentile of control subjects was $15.07 \%$ for caffeine (bitter), $21.9 \%$ for citric acid (sour), $24.66 \%$ for sucrose (sweet), and $31.50 \%$ for $\mathrm{NaCl}$ (salty). The patients with MS identified, on average, fewer stimuli than did the control subjects for each taste quality, as demonstrated by a significant main effect of subject group (MS/control) in all analyses (Fig. 3; $p$ and $\eta^{2}$ values shown in figure). Irrespective of subject group, women outperformed men in identifying the taste qualities [caffeine: respective means $(\mathrm{SEMs})=82.38$ (1.97) and 60.95 (3.10); $p<0.001$, $\left.\eta^{2}=0.186\right)$, sodium chloride: $80.72(1.87)$ and 72.31 
Table 2 Brain regions and MS-related lesions

\begin{tabular}{|c|c|c|c|c|c|}
\hline Brain region & $\begin{array}{l}\text { Number of subjects } \\
\text { with lesions }\end{array}$ & $\begin{array}{l}\text { Mean (SD) } \\
\text { number of lesions }\end{array}$ & $\begin{array}{l}\text { Mean (SD) volume } \\
\text { of lesions }\left(\mathrm{mm}^{3}\right)\end{array}$ & $\begin{array}{l}\text { Mean }(\mathrm{SD}) \text { region } \\
\text { volume }\left(\mathrm{mm}^{3}\right)\end{array}$ & $\begin{array}{l}\text { \% Lesion volume/ } \\
\text { mean region volume }\end{array}$ \\
\hline $\begin{array}{c}\text { Cortex + Cerebral } \\
\text { White Matter L }\end{array}$ & 63 & $32.52(22.75)$ & $6537.50(5283.93)$ & $372977.06(47800.37)$ & 1.75 \\
\hline $\begin{array}{c}\text { Cortex + Cerebral } \\
\text { White Matter R }\end{array}$ & 63 & $31.64(20.25)$ & $6396.37(5106.45)$ & 380037.92 (47377.99) & 1.68 \\
\hline Med Frontal Lobe L & 63 & $14.44(10.59)$ & $1503.67(1511.21)$ & 99267.06 (14813.33) & 1.51 \\
\hline Med Frontal Lobe R & 63 & $13.00(6.99)$ & $1526.88(1623.76)$ & $103422.50(15002.34)$ & 1.48 \\
\hline Temporal Lobe L & 63 & $12.86(8.30)$ & $1170.74(1200.34)$ & $112548.18(13785.93)$ & 1.04 \\
\hline Temporal Lobe R & 61 & $15.03(9.02)$ & $1121.33(1202.92)$ & 119117.01 (14855.76) & 0.94 \\
\hline Med Temp Lobe L & 58 & $5.27(4.29)$ & $55.39(65.70)$ & 5741.75 (715.49) & 0.96 \\
\hline Med Temp Lobe R & 57 & $6.94(5.22)$ & $80.82(86.00)$ & $6381.95(875.38)$ & 1.27 \\
\hline Sup Frontal Lobe L & 60 & $6.16(4.97)$ & $525.02(832.79)$ & 70159.46 (8843.42) & 0.75 \\
\hline Sup Frontal Lobe R & 54 & $4.71(5.01)$ & $401.37(621.85)$ & $66075.80(8208.68)$ & 0.61 \\
\hline Hippocampus L & 48 & $3.42(3.20)$ & $40.27(56.35)$ & 2715.59 (399.95) & 1.48 \\
\hline Hippocampus R & 47 & $3.44(3.24)$ & $37.14(53.42)$ & 2207.70 (343.99) & 1.68 \\
\hline Inf Frontal Lobe L & 46 & $3.87(5.11)$ & $88.73(159.65)$ & $25081.41(3414.52)$ & 0.35 \\
\hline Inf Frontal Lobe R & 48 & $4.16(5.37)$ & $78.00(143.33)$ & $26880.43(3627.71)$ & 0.29 \\
\hline Insular WM L & 39 & $2.02(3.50)$ & $17.58(35.81)$ & $2030.24(335.06)$ & 0.87 \\
\hline Insular WM R & 42 & $2.07(2.52)$ & $16.18(26.16)$ & $1799.54(330.77)$ & 0.90 \\
\hline Insular GM L & 36 & $1.95(3.35)$ & $23.32(66.48)$ & $5012.94(330.77)$ & 0.46 \\
\hline Insular GM R & 39 & $1.95(2.61)$ & $21.03(66.48)$ & $5576.32(883.16)$ & 0.38 \\
\hline Ant Cing Gyr L & 37 & $1.25(1.81)$ & $11.64(22.99)$ & $6286.86(1036.49)$ & 0.19 \\
\hline Ant Cing Gyr R & 36 & $1.51(1.98)$ & $25.36(81.84)$ & $8181.42(1448.92)$ & 0.31 \\
\hline Orb Front Cortex L & 38 & $1.79(2.03)$ & $27.33(45.65)$ & $11378.36(1740.91)$ & 0.24 \\
\hline Orb Front Cortex R & 36 & $1.83(2.55)$ & $23.77(47.58)$ & 10567.77 (1515.99) & 0.22 \\
\hline Thalamus L & 30 & $1.40(2.15)$ & $16.28(39.78)$ & $6358.35(959.02)$ & 0.26 \\
\hline Thalamus $\mathrm{R}$ & 32 & $1.48(2.30)$ & $13.65(43.49)$ & $5743.72(844.77)$ & 0.24 \\
\hline Parietal Opercul L & 29 & $0.70(0.94)$ & $12.59(29.28)$ & $1780.41(427.23)$ & 0.71 \\
\hline Parietal Opercul R & 21 & $0.60(1.13)$ & $14.03(37.83)$ & 1251.13 (353.97) & 1.12 \\
\hline Amygdala L & 5 & $0.13(0.55)$ & $0.63(3.31)$ & $517.78(119.24)$ & 0.14 \\
\hline Amygdala R & 5 & $0.13(0.46)$ & $0.88(4.41)$ & $492.31(145.41)$ & 0.18 \\
\hline Brainstem L & 5 & $0.08(0.27)$ & $1.09(4.71)$ & $11415.70(1535.31)$ & 0.01 \\
\hline Brainstem R & 4 & $0.08(0.33)$ & $2.74(14.92)$ & $10489.84(1439.51)$ & 0.03 \\
\hline Pons L & 4 & $0.06(0.25)$ & $0.53(3.13)$ & $6875.53(1005.03)$ & 0.01 \\
\hline Pons R & 4 & $0.11(0.54)$ & $1.13(6.50)$ & $6346.82(924.35)$ & 0.02 \\
\hline Cerebellum L & 2 & $0.03(0-1)$ & $1.09(7.85)$ & 57195.03 (5996.59) & 0.00 \\
\hline Cerebellum R & 1 & $0.02(0-1)$ & $0.04(0.28)$ & 59252.67 (6598.92) & 0.00 \\
\hline Med Lemniscus L & 0 & $0(0)$ & $0(0)$ & $577.18(103.34)$ & - \\
\hline Med Lemniscus R & 2 & $0.05(0.28)$ & $0.18(1.00)$ & $567.43(85.04)$ & 0.03 \\
\hline Sup Colliculus L & 0 & $0(0)$ & $0(0)$ & 314.79 (73.67) & - \\
\hline Sup Colliculus R & 1 & $0.02(0.13)$ & $0.07(0.58)$ & $335.04(88.31)$ & 0.02 \\
\hline Medulla L & 0 & 0 & 0 & 3202.74 (484.72) & 0.00 \\
\hline Medulla R & 0 & 0 & 0 & 3374.04 (484.72) & 0.00 \\
\hline Inferior Colliculus L & 0 & 0 & 0 & $278.78(68.98)$ & 0.00 \\
\hline Inferior Colliculus R & 0 & 0 & 0 & $256.90(60.73)$ & 0.00 \\
\hline Central Teg. Tract L & 0 & 0 & 0 & $236.82(46.91)$ & 0.00 \\
\hline Central Teg. Tract $\mathrm{R}$ & 0 & 0 & 0 & $212.66(49.85)$ & 0.00 \\
\hline Pont. Parabrach. N. L & 0 & 0 & 0 & 78.99 (22.60) & 0.00 \\
\hline Pont. Parabrach. N. R & 0 & 0 & 0 & $68.89(16.43)$ & 0.00 \\
\hline
\end{tabular}


Table 2 continued

\begin{tabular}{llllll}
\hline Brain region & $\begin{array}{l}\text { Number of subjects } \\
\text { with lesions }\end{array}$ & $\begin{array}{l}\text { Mean (SD) } \\
\text { number of lesions }\end{array}$ & $\begin{array}{l}\text { Mean (SD) volume } \\
\text { of lesions }\left(\mathrm{mm}^{3}\right)\end{array}$ & $\begin{array}{l}\text { Mean (SD) region } \\
\text { volume }\left(\mathrm{mm}^{3}\right)\end{array}$ & $\begin{array}{l}\% \text { Lesion volume/ } \\
\text { mean region volume }\end{array}$ \\
\hline Med. Gen. Body L & 0 & 0 & 0 & $78.18(24.18)$ & 0.00 \\
Med. Gen. Body R & 0 & 0 & 0 & $57.78(18.93)$ & 0.00 \\
Solitary Nucleus L & 0 & 0 & 0 & $57.32(16.42)$ & 0.00 \\
Solitary Nucleus R & 0 & 0 & 0 & $48.04(14.29)$ & 0.00 \\
Bracial Inf. Collicul. L & 0 & 0 & 0 & $36.79(13.06)$ & 0.00 \\
Bracial Inf. Collicul. R & 0 & 0 & 0 & $31.19(9.55)$ & 0.00 \\
\hline
\end{tabular}

Listing is in order of the number of subjects exhibiting lesions within the given brain regions and the \% volume of the brain region involved. The cortex subsumes all lobes excepting the temporal lobes. $N=63$

(2.95); $\left.p=0.017, \eta^{2}=0.032\right)$, citric acid: $73.12(2.00)$ and $\left.61.91(3.13) ; p=0.003, \eta^{2}=0.056\right)$, sucrose: 95.06 (1.30) and $\left.90.60(2.04) ; p=0.062, \eta^{2}=0.022\right)$. The age covariate was significant only for sodium chloride $\left(p=0.014, \eta^{2}=0.034 ;\right.$ all other $\left.p \mathrm{~s} \geq 0.10\right]$, reflecting an overall age-related decline in performance for this stimulus.

In general, the MS-related influences on taste function were found on both the front and the back of the tongue, as no interactions were evident between tongue region and subject group (all $p s>0.20$ ). However, a significant subject group by tongue region by sex interaction was present for caffeine $(p=0.003)$. This reflected the fact that women with MS significantly underperformed their female controls in identifying the bitter taste of caffeine on the front, but not the back, of the tongue [respective MS and control anterior values: 74.59 (2.89) and 86.63 (2.89); $p=0.004$, $\eta^{2}=0.079$, respective posterior values: 82.14 (2.67) and 85.97 (2.67); $\left.p=0.311, \eta^{2}=0.010\right]$, whereas a non-significant trend in the opposite direction was present for the men [respective anterior MS and control values: 60.23 (6.28) and $60.41(6.28), p=0.984, \eta^{2}<0.001$; respective posterior MS and control values: 54.70 (5.73) and 69.12 (5.73), $\left.p=0.083, \eta^{2}=0.070\right]$.

\section{Intensity ratings}

The mean intensity rating of the MS patients was significantly lower than that of the controls for caffeine [respective means $(\mathrm{SEMs})=4.95(0.22)$ and $4.41(0.22)$, $p<0.05, \eta^{2}=0.086$ ), but not for any other tastant ( $p s>0.20)$. Significant main effects of sex were present for all tastants, reflecting larger intensity ratings given by women than by men [respective female and male means (SEMs) for sucrose, citric acid, caffeine and sodium chloride: $5.77(0.15)$ and $4.90 \quad(0.23), \quad p=0.002$, $\eta^{2}=0.067 ; 5.06(0.14)$ and $4.10(0.23), p<0.0001$, $\eta^{2}=0.086 ; 5.33(0.15)$ and $4.03(0.24), p<0.0001$, $\eta^{2}=0.133 ; 5.29(0.15)$ and $4.64(0.24), p=0.023$, $\left.\left.\eta^{2}=0.037\right)\right]$.

\section{Relationship of taste test measures to brain lesions within the MS group}

Because lesions were absent or sparse in a number of the targeted brain structures and a range of lesion values was needed to establish meaningful correlation coefficients with the taste measures, we focused our correlation analyses on brain structures in which lesions were present in at least 21 of the 63 MS patients (Table 2). The Spearman correlations between lesion volumes in the primary brain regions and the taste identification test scores for the left and right sides of the tongue are presented in Table 3. It is apparent that the taste identification scores were correlated, albeit weakly, with lesion volumes within the larger brain structures-structures in which typically more than $1 \%$ of their volume was comprised of lesions (Table 2). No systematic associations between the side of the lesions and the side of the tongue that was tested were observed. Only four significant negative correlations were found between the number of lesions and the taste identification test scores, in contrast to the 40 significant negative coefficients shown in Table 3 for lesion volumes. Two were between the left side sour identification scores and the number of lesions in the left and right superior frontal lobes (both $r \mathrm{~s}=-0.26, p \mathrm{~s}<0.025)$, one was between the left side bitter scores and the number of lesions in the right superior frontal lobe $(r=-0.24, p<0.05)$ and one was between the left side sweet identification test score and the number of lesions in the right anterior cingulate gyrus $(r=-0.29, p<0.05)$.

As would be expected from our finding of fewer significant differences in the taste intensity ratings between 


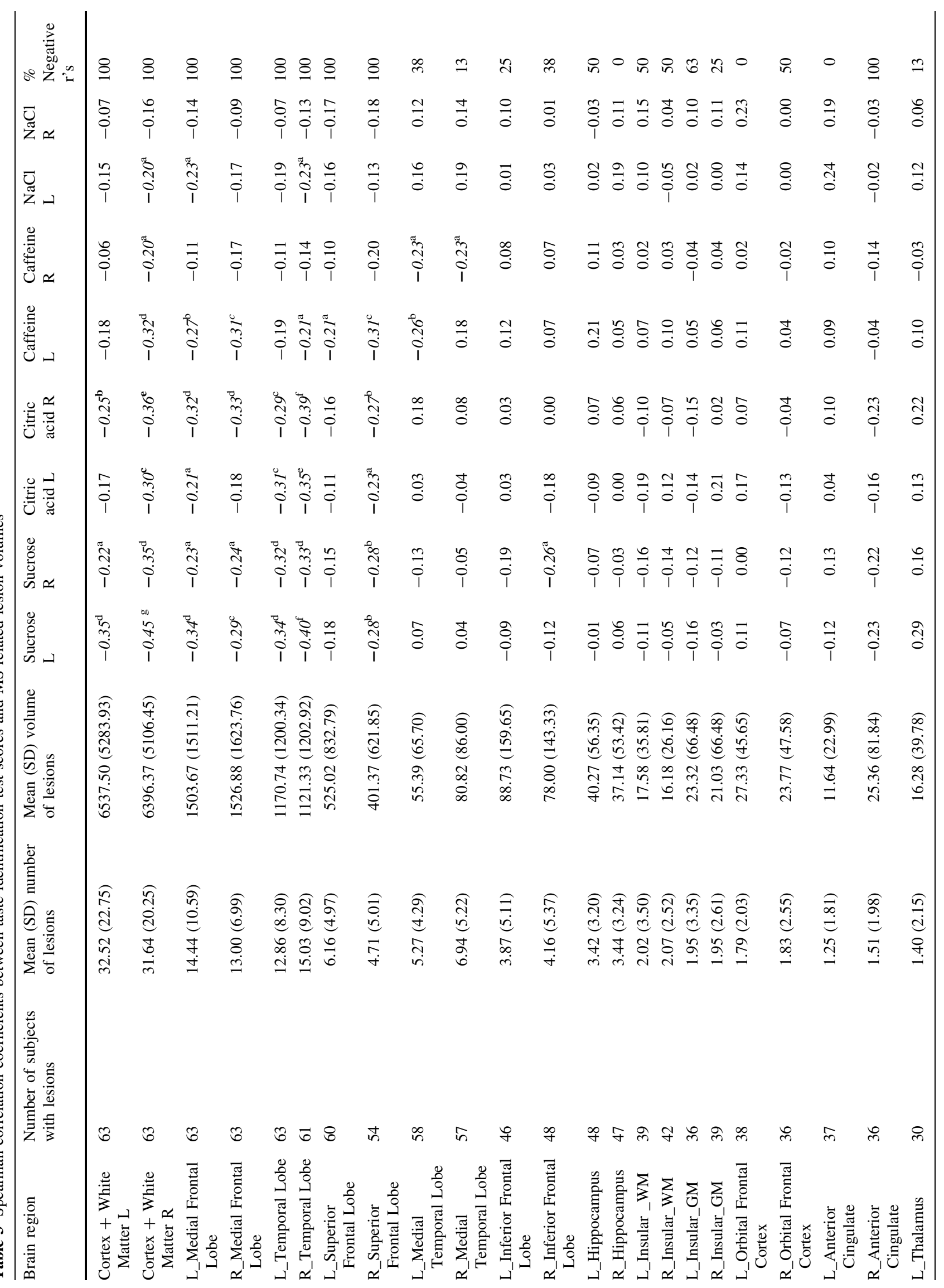




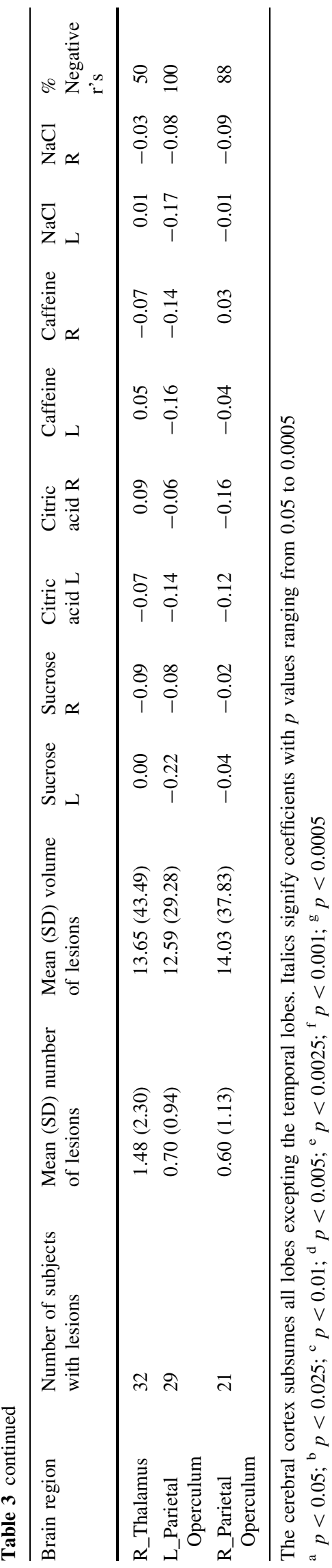

the MS patients and the controls, i.e., an association only for caffeine, we found few correlations among lesion volumes and the intensity ratings, with only 8 of 216 coefficients being significant, albeit all in the negative direction. Interestingly, none of these correlations reached the nominal 0.05 alpha level for caffeine, the only stimulus for which a significant difference appeared in the mean intensity ratings between the MS patients and the controls. Five of the correlations were related to lesions in the right superior frontal lobe, one in the right cortex, and two in the left cortex (Table 4). Correlations between the number of lesions and intensity ratings were similarly sparse. Thus, only two significant negative correlations were observed: sour intensity ratings on the left side of the tongue with lesion numbers in the left and right frontal lobes (both $r \mathrm{~s}=-0.28, \quad p \mathrm{~s}<0.025)$. All coefficients computed between the lesion numbers in these two brain structures and the 8 taste test measures were in the expected negative direction $(16 / 16 ; 100 \%)$.

A small subset, i.e., 4-5, of the patients had lesions within the brainstem and/or pons that were lateralized to one side or the other. Since an initial segment of the taste pathway passes through these structures, it was conceivable that taste function might be more compromised on the side of the tongue ipsilateral to the location of the lesions. However, the average taste scores on the side of the tongue ipsilateral to the side of the brainstem lesions did not differ from that of the average taste scores on the tongue contralateral to the lesion side, providing no support for the concept that, in MS, unilateral lesion activity within the brainstem differentially altered taste function on the left or the right sides of the tongue.

\section{Discussion}

This research represents the most comprehensive study performed to date on the influences of MS on the ability to taste. It determined whether associations are present between taste function and quantitative measures of brain lesions in MS and whether MS differentially influences various taste qualities and taste function mediated by $\mathrm{CN}$ VII (anterior 2/3rds of the tongue) and CN IX (posterior third of the tongue) afferents. MS significantly influenced the ability to identify tastants for all four classic taste qualities on both anterior and posterior regions of the tongue. Additionally, MS altered intensity ratings for the tastant caffeine. Taste identification test scores were correlated with the lesion volumes in the frontal and temporal lobes and a sizable proportion of the MS patients exhibited scores falling below the 5th percentile of those of matched controls. No lateralized taste deficits relative to lateralized lesions within the pons, brainstem, or elsewhere were 
apparent. The fifth taste quality that is generally recognized today, umami, was not tested in this study, although presumably it would also be influenced by MS since deficits in umami taste have been found to be related to deficits in other taste qualities in clinical studies (e.g., [29]). In accord with earlier taste research in normal subjects [30], women generally outperformed men on all of our tests in both the MS and control groups, conceivably reflecting the fact that women possess a larger number of taste papillae and taste buds than do men [31].

Although the 15-32\% prevalence rate for taste dysfunction relative to controls was about half of that generally found for optic neuritis, a hallmark in the diagnosis of MS [32], it is nonetheless a substantial number. This suggests that altered taste function, albeit modest in magnitude and less noticeable than changes in vision, is a relatively common feature of MS. In general, most of our prevalence estimates of MS-related taste dysfunction (caffeine, $15.07 \%$; citric acid, $21.9 \%$; sucrose, $24.66 \% ; \mathrm{NaCl}, 31.50 \%$ ) are higher than the 8 to $\sim 22 \%$ prevalence estimates noted by other investigators who have performed quantitative or semiquantitative taste testing of MS patients [5, 7, 10-12, 33]. Presumably this reflects differences in the criteria for defining dysfunction, the types of tastants and test procedures employed, sample sizes, and other factors. The low prevalence of taste dysfunction reported in numerous surveys presumably reflects the fact that most persons are unaware of less-than-total or near-total taste loss [8]. Such lack of awareness also is evident in the general population, as well as in Alzheimer's disease and Parkinson's disease. However, lack of awareness does not avert clinical significance, since such losses can be harbingers for nutritional deficits [34] and higher subsequent mortality [35, 36].

An important finding of the present study is that MS influenced the ability to identify all four classic taste qualities (Fig. 1). Most previous MS studies have not distinguished between taste qualities [5, 10, 11] or have reported that the deficits were limited to only a few such qualities. For example, Catalanotto et al. [37] noted adverse influences for taste quality identification and suprathreshold intensity perception only for $\mathrm{NaCl}$ (salty) and quinine hydrochloride (bitter); sweet (sucrose) and sour (citric acid) perception was not similarly affected. Our research suggests that the influence of MS is more widespread, although it is of interest that the only stimulus for which we observed an MS-related intensity deficit was for the bitter tasting agent caffeine, in accord with one of the observations of Catalanotto et al.

Our finding that MS impacted taste identification ability more than intensity perception conceivably reflects several factors. First, higher brain regions-regions with the most MS-related lesion activity — may influence taste quality more than perceived strength. For example, one functional imaging

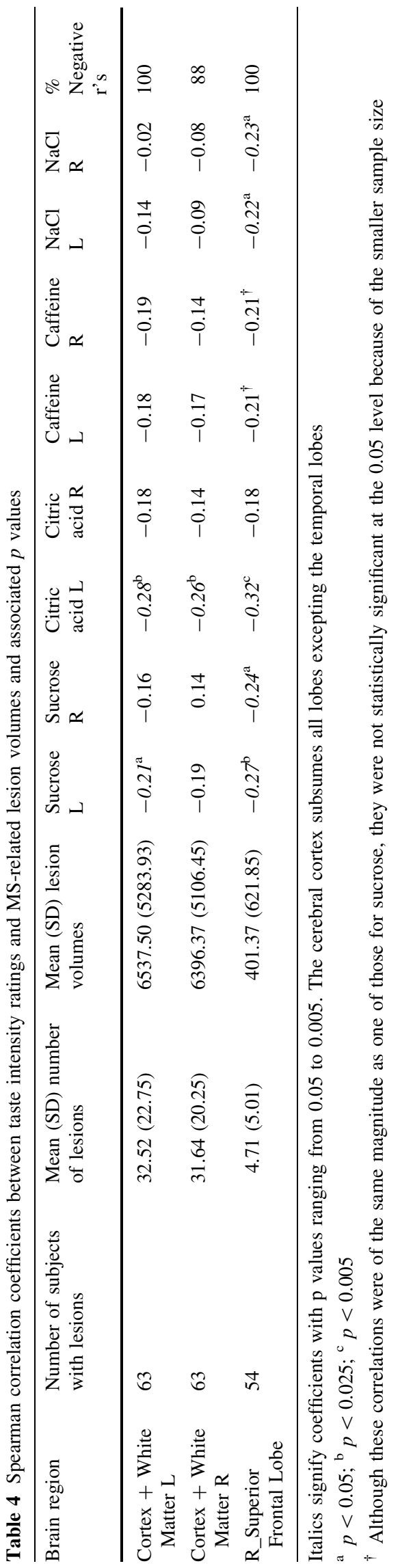


study found the anterior insula/operculum and caudolateral orbitofrontal cortex to be less sensitive to stimulus intensity than the amygdala, pons, and middle insula [38]. Second, our intensity measure, based upon a single concentration for each of four tastants, may have lacked the sensitivity to detect a broader range of MS-related intensity deficits. However, it should be noted that both threshold and identification tests appear to be more sensitive to chemosensory deficits than suprathreshold scaling procedures. A classic example is a magnitude estimation study that completely missed the wellestablished age-related deficit observed using tests of odor identification and threshold sensitivity [39]. A recent metaanalysis of studies of taste function in older persons found taste threshold deficits in $94 \%$ of the studies evaluated (17/ 18), whereas suprathreshold intensity deficits were observed in only $64 \%$ of the evaluated studies (16/25) [40]. Nevertheless, the question remains as to what degree the smaller decrements observed in suprathreshold intensity measures represent methodological or physiological processes.

Although we observed very few lesions within the pons and brainstem, those that were observed were lateralized. Our finding that this lateralization was not mirrored by lateralized taste function may reflect the fact that such lesions are not independent of bilateral lesions found elsewhere in the brain. Under the assumption that the latter lesions influence the ability to taste, any unilateral influences at the level of the brainstem would likely be swamped. Had lesions other than the brainstem and pons lesions not been present, disproportionate unilateral dysfunction would have been expected. Thus, Onoda and Ikeda noted, in a review of 15 non-MS clinical cases of taste function, that unilateral gustatory impairment occurred with unilateral injury to any one of several brain structures, namely the pons ( 8 cases), thalamus ( 5 cases), midbrain (one case), and internal capsule (one case) [41]. These authors surmised, based on the side of the lesions and their effect on either unilateral or contralateral gustatory function, that the gustatory pathways ascend homolaterally from the medulla, cross in their course from the pons to the midbrain, and synapse within the contralateral thalamus. Bilaterally diminished taste responses have been observed in patients with unilateral midbrain and unilateral paramedian thalamic infarcts [42, 43].

Another important finding of our study is that the taste identification scores were negatively correlated with lesion volumes in the cortex, frontal lobe, and temporal lobes. Similar associations were less evident in other brain structures or for taste intensity ratings. Although the correlation coefficients are moderate, they are similar in magnitude to those reported by others between MS lesions and cognitive measures [44, 45]. Like some other studies (e.g., [46]), we found lesion volumes to be more strongly correlated with the dependent measures than lesion numbers, conceivably reflecting the fact that lesions can vary in size, with some spanning larger sectors of neural tissue than others [47].

It is of significance that a number of brain structures intimately associated with taste function had no or few MS-related lesions, implying that the adverse influence of MS on taste largely involves higher brain structures. Nevertheless, lesions made up $<2 \%$ of the volume of the large brain regions with the most lesion activity, suggesting that only a minority of such lesions impact neural pathways related to taste function, potentially explaining why normal taste function is present in most MS patients. Other explanations of weak associations between taste test scores and MS-related lesions include the potential redundancy and plasticity of neural circuits in higher brain regions [48] and the underestimation of disease burden due to generalized changes in normally appearing CNS white matter [49, 50]. Importantly, one cannot rule out the possibility that much of the influence of MS on taste function is not directly related to observable lesion activity but is due to more subtle damage to membrane channels. At the receptor level, taste perception depends upon movement of $\mathrm{Na}^{+}$and $\mathrm{H}^{+}$ions through specialized membrane channels, either directly as in the case of salty and sour tastants (e.g., the amiloride-sensitive $\mathrm{Na}^{+}$channel and ENaC-like channels) [51] or indirectly, as in the case of sweet- and bitter-tasting stimuli that activate G-protein coupled receptors [52-54]. MS is known to influence both ionotropic and metabotropic forms of neural transmission and could conceivably exert some of its effects at the level of the cell membrane $[55,56]$.

Among the strongest influences on taste function observed in this study was that of sex. Women generally outperformed men on all of our tests in both the MS and control groups. This is in accord with sex differences noted in other taste studies [30], as well as the fact that women typically outperform men on a wide range of sensory tasks, including ones involving hearing, olfaction, and touch [57]. Women have been found to possess a larger number of taste papillae and taste buds than men [31] and, after correcting for cranial volume, have larger frontal and medial paralimbic cortices. Men, on the other hand, have larger relative volumes of the hypothalamus, frontomedial cortex, and amygdala [58]. To what degree such factors dictate the sex differences observed in taste function is unknown, although being a female may afford some degree of protection from adverse influences on the taste system.

The present study has both strengths and weaknesses. Among its strengths are its relatively large sample size, sophisticated regional taste testing of both sexes, and assessments of associations between the taste test scores and the MSrelated lesions, as measured by MRI. Multiple tongue regions and stimuli were evaluated, allowing for a determination of regional deficits in taste function and their associations with MS-related CNS brain lesions. Among its weaknesses are (a) its focus on only the four classic taste qualities, despite the plethora 
of available taste stimuli, including numerous sodium and potassium salts, (b) its evaluation of only suprathreshold taste perception, which may be less sensitive than taste threshold measures, and (c) the calculation of a relatively large number of correlations between the taste measures and the brain lesion activity, potentially inflating the type I error rate. That being said, the observed correlations were logically consistent and were in the expected negative direction. As noted above, it is of interest that in our patient population lesions were sparse in brain structures generally associated with the primary taste projections, namely the brainstem, pons, and medulla, yet clearcut associations between lesion volumes and taste function were evident throughout higher brain structures.

In summary, the present study clearly demonstrates that MS is commonly associated with decrements in the ability to identify all four classic taste qualities within both anterior and posterior regions of the tongue. Female MS patients, like women in general, identified tastants more accurately and rated their perception as more intense than did male MS patients. Our study demonstrates that lesion volumes within large sectors of the frontal and temporal lobes are correlated with functional measures of taste. In light of the discovery of taste receptor proteins within the alimentary tract [51], future research may be of value in determining whether MS-related changes in oral taste function are associated with gastric motility, changes in microbiota, and other MS-related alterations in which extraoral taste receptors may play a role [59].

Acknowledgments We are indebted to the subjects who participated in this study. We thank Nancy A. Lee, M.D., Andre S. Souza, M.D., and Hussam Tallab, M.D., for their contributions to this work, and Greg Smutzer, Ph.D., for comments on an earlier version of the manuscript. Special thanks goes out to Inna Chung, who played a significant role in preparing the manuscript for journal submission. This research was supported by the U.S. National Institutes of Health Grants RO1 DC 02974 (Doty), R01 NS 37172 (Doty), and R01 NS070906 (Pham).

\section{Compliance with ethical standards}

Conflicts of interest None of the authors of this study declare any conflicts of interest.

\section{References}

1. Sorgun MH, Yucesan C, Tegin C (2014) Is malnutrition a problem for multiple sclerosis patients? J Clin Neurosci 21:1603-1605

2. Müller R (1949) Studies on disseminated sclerosis with special reference to symptomatology, course and prognosis. Acta Med Scand Suppl 20:68-75

3. Kurtzke JF, Beebe GW, Nagler B, Auth TL, Kurland LT, Nefzger MD (1972) Studies on the natural history of multiple sclerosis. Act Neurol Scand 48:19-46

4. Kahana E, Leibowitz U, Alter M (1973) Brainstem and cranial nerve involvement in multiple sclerosis. Act Neurol Scand 49:269-279
5. Wender M, Szmeja Z (1971) Badanie sluchu, czynnosci narzadu przedsionkowego, smaku I wechu u chorych na stwardnienie rozsiane. Neurol Neurochir Pol 5:179-184

6. Bromley SM, Doty RL (2015) Clinical disorders affecting taste: an update. In: RL Doty (ed) Handbook of Olfaction and Gustation. John Wiley Sons, Hoboken, pp 887-910

7. Deems DA, Doty RL, Settle RG, Moore-Gillon V, Shaman P, Mester AF, Kimmelman CP, Brightman VJ, Snow JB Jr (1991) Smell and taste disorders, a study of 750 patients from the University of Pennsylvania Smell and Taste Center. Arch Otolaryngol Head Neck Surg 117:519-528

8. Soter A, Kim J, Jackman A, Tourbier I, Kaul A, Doty RL (2008) Accuracy of self-report in detecting taste dysfunction. Laryngoscope 118:611-617

9. Rollin H (1976) Gustatory disturbances in multiple sclerosis. Laryngol Rhinol Otol 55:678-681 (German)

10. Dahlslett SB, Goektas O, Schmidt F, Harms L, Olze H, Fleiner F (2012) Psychophysiological and electrophysiological testing of olfactory and gustatory function in patients with multiple sclerosis. Eur Arch Otorhinolaryngol 269: 1163-1169

11. Fleiner F, Dahlslett SB, Schmidt F, Harms L, Goektas O (2010) Olfactory and gustatory function in patients with multiple sclerosis. Am J Rhinol Allergy 24:e93-e97

12. Schmidt FA, Goktas O, Harms L, Bohner G, Erb K, Dahlslett B, Fleiner F (2011) Structural correlates of taste and smell loss in encephalitis disseminata. PLoS One 6:e19702

13. Doty RL, Tourbier I, Davis S, Rotz J, Cuzzocreo JL, Treem J, Shephard N, Pham DL (2012) Pure-tone auditory thresholds are not chronically elevated in multiple sclerosis. Behav Neurosci 126:314-324

14. Doty RL, Haxel BR (2005) Objective assessment of terbinafineinduced taste loss. Laryngoscope 115:2035-2037

15. Stinton N, Atif MA, Barkat N, Doty RL (2010) Influence of smell loss on taste function. Behav Neurosci 124:256-264

16. Doty RL, Cometto-Muniz JE, Jalowayski AA, Dalton P, KendalReed M, Hodgson M (2004) Assessment of upper respiratory tract and ocular irritative effects of volatile chemicals in humans. Crit Rev Toxicol 34:85-142

17. Goldszal AF, Davatzikos C, Pham DL, Yan MX, Bryan RN, Resnick SM (1998) An image-processing system for qualitative and quantitative volumetric analysis of brain images. J Comput Assist Tomogr 22:827-837

18. Bazin PL, Cuzzocreo JL, Yassa MA, Gandler W, McAuliffe MJ, Bassett SS, Pham DL (2007) Volumetric neuroimage analysis extensions for the MIPAV software package. J Neurosci Methods 165:111-121

19. Pham DL, Prince JL (1999) Adaptive fuzzy segmentation of magnetic resonance images. IEEE Trans Med Imaging 18:737-752

20. Pham DL (2001) Spatial models for fuzzy clustering. Comput Med Imaging Graph 84:285-297

21. Van Leemput K, Maes F, Vandermeulen D, Colchester A, Suetens P (2001) Automated segmentation of multiple sclerosis lesions by model outlier detection. IEEE Trans Med Imaging 20:677-688

22. Van LK, Maes F, Vandermeulen D, Colchester A, Suetens P (2001) Automated segmentation of multiple sclerosis lesions by model outlier detection. IEEE Trans Med Imaging 20:677-688

23. Shen D, Davatzikos C (2002) HAMMER: hierarchical attribute matching mechanism for elastic registration. IEEE Trans Med Imaging 21:1421-1439

24. Wilkinson L (1990) SYSTAT: the system for statistics. SYSTAT, Inc., Evanston

25. Perneger TV (1998) What's wrong with Bonferroni adjustments. BMJ 316:1236-1238 
26. Rothman KJ (1990) No adjustments are needed for multiple comparisons. Epidemiology 1:43-46

27. Onoda K, Ikeda M (1999) Gustatory disturbance due to cerebrovascular disorder. Laryngoscope 109:123-128

28. Shikama Y, Kato T, Nagaoka U, Hosoya T, Katagiri T, Yamaguchi K, Sasaki H (1996) Localization of the gustatory pathway in the human midbrain. Neurosci Lett 218:198-200

29. McMahon EJ, Campbell KL, Bauer JD (2014) Taste perception in kidney disease and relationship to dietary sodium intake. Appetite 83:236-241

30. Doty RL (1978) Gender and reproductive state correlates of taste perception in humans. In: McGill TE, Dewsbury DA, Sachs BD (eds) Sex and behavior: status and prospectus. Plenum, New York, pp 337-362

31. Bartoshuk LM, Duffy VB, Miller IJ (1994) PTC/PROP tasting: anatomy, psychophysics, and sex effects. Physiol Behav 56:1165-1171

32. Brass SD, Zivadinov R, Bakshi R (2008) Acute demyelinating optic neuritis: a review. Front Biosci 13:2376-2390

33. Grénman R (1985) Involvement of the audiovestibular system in multiple sclerosis. An otoneurologic and audiologic study. Acta Otolaryngol Suppl 420:1-95

34. Lee J, Tucker RM, Tan SY, Running CA, Jones JB, Mattes RD (2015) Nutritional implications of taste and smell dysfunction. In: Doty RL (ed) Handbook of olfaction and gustation. Wiley, New York, pp 831-863

35. Devanand DP, Lee S, Manly J, Andrews H, Schupf N, Masurkar A, Stern Y, Mayeux R, Doty RL (2015) Olfactory identification deficits and increased mortality in the community. Ann Neurol 78:401-411

36. Solemdal K, Moinichen-Berstad C, Mowe M, Hummel T, Sandvik L (2014) Impaired taste and increased mortality in acutely hospitalized older people. Chem Senses 39:263-269

37. Catalanotto FA, Dore-Duffy P, Donaldson JO, Testa M, Peterson M, Ostrom KM (1984) Quality-specific taste changes in multiple sclerosis. Ann Neurol 16:611-615

38. Small DM, Gregory MD, Mak YE, Gitelman D, Mesulam MM, Parrish T (2003) Dissociation of neural representation of intensity and affective valuation in human gustation. Neuron 39:701-711

39. Rovee CK, Cohen RY, Shlapack W (1975) Life-span stability in olfactory sensitivity. Dev Psychol 11:311-318

40. Methven L, Allen VJ, Withers CA, Gosney MA (2012) Ageing and taste. Proc Nutr Soc 71:1-10

41. Onoda K, Kobayakawa T, Ikeda M, Saito S, Kida A (2005) Laterality of human primary gustatory cortex studied by MEG. Chem Senses 30:657-666

42. Tsivgoulis G, Ioannis H, Vadikolias K, Galetta SL, Piperidou C (2011) Bilateral ageusia caused by a unilateral midbrain and thalamic infarction. J Neuroimaging 21:263-265

43. Nakajima M, Ohtsuki T, Minematsu K (2010) Bilateral hypogeusia in a patient with a unilateral paramedian thalamic infarction. J Neurol Neurosurg Psychiatry 81:700-701

44. Yildiz M, Tettenborn B, Radue EW, Bendfeldt K, Borgwardt S (2014) Association of cognitive impairment and lesion volumes in multiple sclerosis-a MRI study. Clin Neurol Neurosurg 127:54-58

45. Lund H, Jonsson A, Andresen J, Rostrup E, Paulson OB, Sorensen PS (2012) Cognitive deficits in multiple sclerosis: correlations with $\mathrm{T} 2$ changes in normal appearing brain tissue. Acta Neurol Scand 125:338-344

46. Harrison DM, Roy S, Oh J, Izbudak I, Pham D, Courtney S, Caffo B, Jones CK, van Zijl P, Calabresi PA (2015) Association of cortical lesion burden on 7-T magnetic resonance imaging with cognition and disability in multiple sclerosis. JAMA Neurol 72:1004-1012

47. Dolezal O, Dwyer MG, Horakova D, Havrdova E, Minagar A, Balachandran S, Bergsland N, Seidl Z, Vaneckova M, Fritz D, Krasensky J, Zivadinov R (2007) Detection of cortical lesions is dependent on choice of slice thickness in patients with multiple sclerosis. Int Rev Neurobiol 79:475-489

48. Reddy H, Narayanan S, Arnoutelis R, Jenkinson M, Antel J, Matthews PM, Arnold DL (2000) Evidence for adaptive functional changes in the cerebral cortex with axonal injury from multiple sclerosis. Brain 123(Pt 11):2314-2320

49. Loevner LA, Grossman RI, Cohen JA, Lexa FJ, Kessler D, Kolson DL (1995) Microscopic disease in normal-appearing white matter on conventional MR images in patients with multiple sclerosis: assessment with magnetization-transfer measurements. Radiology 196:511-515

50. Gasperini C, Horsfield MA, Thorpe JW, Kidd D, Barker GJ, Tofts PS, MacManus DG, Thompson AJ, Miller DH, McDonald WI (1996) Macroscopic and microscopic assessments of disease burden by MRI in multiple sclerosis: relationship to clinical parameters. J Magn Reson Imaging 6:580-584

51. Chaudhari N, Roper SD (2010) The cell biology of taste. J Cell Biol 190:285-296

52. Chandrashekar J, Hoon MA, Ryba NJ, Zuker CS (2006) The receptors and cells for mammalian taste. Nature 444:288-294

53. Meyerhof W, Batram C, Kuhn C, Brockhoff A, Chudoba E, Bufe B, Appendino G, Behrens M (2010) The molecular receptive ranges of human TAS2R bitter taste receptors. Chem Senses 35:157-170

54. Roudnitzky N, Bufe B, Thalmann S, Kuhn C, Gunn HC, Xing C, Crider BP, Behrens M, Meyerhof W, Wooding SP (2011) Genomic, genetic and functional dissection of bitter taste responses to artificial sweeteners. Hum Mol Genet 20:3437-3449

55. Schattling B, Steinbach K, Thies E, Kruse M, Menigoz A, Ufer F, Flockerzi V, Bruck W, Pongs O, Vennekens R, Kneussel M, Freichel M, Merkler D, Friese MA (2012) TRPM4 cation channel mediates axonal and neuronal degeneration in experimental autoimmune encephalomyelitis and multiple sclerosis. Nat Med 18:1805-1811

56. Bouafia A, Golmard JL, Thuries V, Sazdovitch V, Hauw JJ, Fontaine B, Seilhean D (2014) Axonal expression of sodium channels and neuropathology of the plaques in multiple sclerosis. Neuropathol Appl Neurobiol 40:579-590

57. Velle W (1987) Sex differences in sensory functions. Perspect Biol Med 30:490-522

58. Goldstein JM, Seidman LJ, Horton NJ, Makris N, Kennedy DN, Caviness VS Jr, Faraone SV, Tsuang MT (2001) Normal sexual dimorphism of the adult human brain assessed by in vivo magnetic resonance imaging. Cereb Cortex 11:490-497

59. Ochoa-Reparaz J, Mielcarz DW, Begum-Haque S, Kasper LH (2011) Gut, bugs, and brain: role of commensal bacteria in the control of central nervous system disease. Ann Neurol 69:240-247 